\section{REFERENCES}

1. Collett RW, Edwards JE. Persistent truncus arteriosus: a classification according to anatomic types. Surg Clin North Am 1949;29:1245-70.

2. Van Praagh R, Van Praagh S. The anatomy of common aorticopulmonary trunk (truncus arteriosus communis) and its embryologic implications: a study of 57 necropsy cases. Am J Cardiol 1965;16:406-25.

3. Crupi G, Macartney FJ, Anderson RH. Persistent truncus arteriosus: a study of autopsy material with special reference to its definition and morphogenesis. Am J Cardiol 1977;40: 569-78.

4. Van Mierop LH, Patterson DF, Schnarr WR. Pathogenesis of persistent truncus arteriosus in light of observations made in a dog embryo with the anomaly. Am J Cardiol 1978;41: $755-62$.

5. Bharati S, Lev M. Truncus arteriosus communis. In: The pathology of congenital heart disease: a personal experience with more than 6,300 congenitally malformed hearts. Armonk (NY): Futura Publishing, 1996:353-80.

6. Swift LF, Shimomura S, Ryan SF, Van Praagh R. New type of truncus arteriosus communis with two semilunar valves, aortic valvar atresia and no ventricular septal defect. Circulation 1969;40(Suppl):III199.

7. Matsuoka R, Van Praagh S, Van Praagh R. Rare types of truncus arteriosus communis. Circulation 1982;66:II359.

8. Alves PM, Ferrari AH. Common arterial trunk arising exclusively from the right ventricle with hypoplastic left ventricle and intact ventricular septum. Int $\mathbf{J}$ Cardiol 1987;16:99-102.

9. Zeevi B, Dembo L, Berant M. Rare variant of truncus arteriosus with intact ventricular septum and hypoplastic right ventricle. Br Heart J 1992;68:214-5.

10. Meisner H, Schmidt-Habelmann P, Sebening F, Klinner W. Surgical correction of aorto-pulmonary septal defects: a review of the literature and report of eight cases. Dis Chest 1968;53:750-8

11. Berry TE, Bharati S, Muster AJ, et al. Distal aortopulmonary septal defect, aortic origin of the right pulmonary artery, intact ventricular septum, patent ductus arteriosus and hypoplasia of the aortic isthmus: a newly recognized syndrome. Am J Cardiol 1982;49:108-16.

\title{
ULTRAFAST COMPUTED TOMOGRAPHY IN INFECTIOUS PSEUDOANEURYSM OF THE LEFT VENTRICULAR OUTFLOW TRACT
}

\author{
Luis D. Berrizbeitia, MD, and William A. Anderson, MD, Browns Mills and New Brunswick, N.J.
}

Infectious pseudoaneurysm of the left ventricular outflow tract is a potentially catastrophic complication of aortic and mitral valve surgery. Successful surgical management relies on knowledge of the exact location and extension of the pseudoaneurysmal cavity and involvement of the mitral-aortic intervalvular fibrosa. ${ }^{1}$ We describe a case of infectious pseudoaneurysm occurring 4 years after aortic valve replacement for Streptococcus endocarditis. The pseudoaneurysmal cavity extended laterally and posteriorly from the left coronary cusp, inferior to the pulmonary artery and lateral and superior to the wall of the left atrium, left ventricle, and left ventricular outflow tract. Diagnostic evaluation consisted of echocardiography, right heart catheterization, coronary angiography, and ultrafast computed tomography (CT). The latter facilitated the surgical repair by providing a dynamic,

From the Department of Thoracic and Cardiovascular Surgery, Deborah Heart and Lung Center, Browns Mills, N.J., and UMDNJ-Robert Wood Johnson Medical School, New Brunswick, N.J.

Received for publication Jan. 20, 1997; accepted for publication Jan. 28, 1997.

Address for reprints: William K. Anderson, MD, Deborah Heart and Lung Center, 200 Trenton Rd., Browns Mills, NJ 08015.

J Thorac Cardiovasc Surg 1997;114:138-9

Copyright (C) 1997 by Mosby-Year Book, Inc.

$0022-5223 / 97 \$ 5.00+0 \quad \mathbf{1 2 / 5 4 / 8 0 7 3 2}$ three-dimensional picture of the pseudoaneurysmal cavity and its relationships with adjacent structures.

Clinical summary. A 40-year-old man was referred to the hospital 4 years after aortic valve replacement with a $25 \mathrm{~mm}$ St. Jude Medical valve (St. Jude Medical, Inc., St. Paul, Minn.) for Streptococcus viridans endocarditis. Two months before admission, the patient had shortness of breath, recurrent fever, and confusion. A transesophageal echocardiogram (TEE) revealed a cavity adjacent to the left side of the aortic anulus. CT scan revealed splenic infarcts, renal embolism, hepatomegaly, and right pleural effusion. Blood cultures grew Staphylococcus aureus. Sodium nafcillin was given intravenously for 6 weeks with subsequent negative blood cultures. One month before admission an echocardiogram revealed deformity of the aortic root consistent with a cavity that compressed the pulmonary artery and expanded during systole. Doppler echocardiography showed flow into and out of the cavity. Ultrafast CT revealed a well-seated aortic prosthesis with the ring at the aortic anulus. Administration of contrast material demonstrated a periannular cavity tracking posteriorly and inferiorly, extending laterally over the top of the left atrium (Fig. 1). Pulmonary capillary wedge pres sure was $22 \mathrm{~mm} \mathrm{Hg}$ and pulmonary artery pressure was $50 / 30 \mathrm{~mm} \mathrm{Hg}$. The aortogram revealed one plus central aortic regurgitation without perivalvular leak. Coronary arteriography revealed dynamic obliteration of the left anterior descending and circumflex coronary arteries with a smooth, proximal high-grade stenosis during systole and 
returning to normal during diastole. Levophase showed dilatation of the left atrium with a communication between the left ventricular outflow tract and a large pseudoaneurysm.

At operation, a multilobulated cystic structure was seen arising from the junction between the left ventricular outflow tract and the posterior aspect of the aortic root. TEE demonstrated a communication with the left ventricular outflow tract. The prosthetic valve was removed, revealing a $8 \times 10 \mathrm{~cm}$ defect below the aortic anulus between the left and the noncoronary cusps. The corresponding area of the left ventricular outflow tract had disconnected from the aortic anulus and was being held by a rim of fibrous tissue. The pseudoaneurysm extended below the pulmonary artery and laterally and superior to the left atrial appendage. No gross evidence of sepsis was apparent, and intraoperative Gram stains were negative for microorganisms. The defect was repaired with a Hemashield Dacron patch (Meadox Medicals, Inc., Malvern, Pa.) sutured to the fibrotic rim of the left ventricular outflow tract and the aortic anulus with interrupted pledget-supported braided polyester sutures (Ethibond, Ethicon, Inc., Somerville, N.J.). A 25 mm expandedcuff St. Jude Medical valve was implanted. Shortly after separation from cardiopulmonary bypass, left ventricular failure developed. The pseudoaneurysm sac, which was previously decompressed, was now tense and apparently externally compressing the coronary arteries. This sac was incised and decompressed and left ventricular function returned to normal. Postoperative TEE showed normal flows. Recovery was uneventful and the patient was discharged 10 days after the operation.

Discussion. Surgical treatment of infectious pseudoaneurysm of the left ventricular outflow tract consists of debridement of all nonviable tissue, exclusion of the periannular cavity from the circulation, firm closure of the cavity by direct suture or patch closure, and reconstruction of the aortic anulus to provide adequate seating of the prosthetic valve. ${ }^{2}$ The most common site for development of an infectious pseudoaneurysm is the mitral-aortic intervalvular fibrosa. ${ }^{1}$ TEE has become the diagnostic procedure of choice for noninvasive evaluation of prosthetic valves. It provides a two-dimensional image across the heart and quantifies flows and pressures across the valves and between the heart chambers, the great vessels, and the pseudoaneurysm. A left ventriculogram may demonstrate an intervalvular pseudoaneurysm but is often not obtained because doing so implies crossing the prosthetic aortic valve. ${ }^{3,4}$ Although coronary artery disease is infrequent in the age group of patients with infectious endocarditis, dynamic coronary obstruction by a pseudoaneurysm has been documented. ${ }^{5}$ The combination of aortic regurgitation and dynamic coronary obstruction may cause severe myocardial ischemia with coronary blood flow reduced during diastole and systole.

Ultrafast CT scan has the advantage of sequentially demonstrating all chambers of the heart after a single intravenous administration of contrast material, providing a dynamic, three-dimensional picture of the aortic area and ventricular cavities. In the present case, ultrafast CT demonstrated the pseudoaneurysmal cavity and its rela-

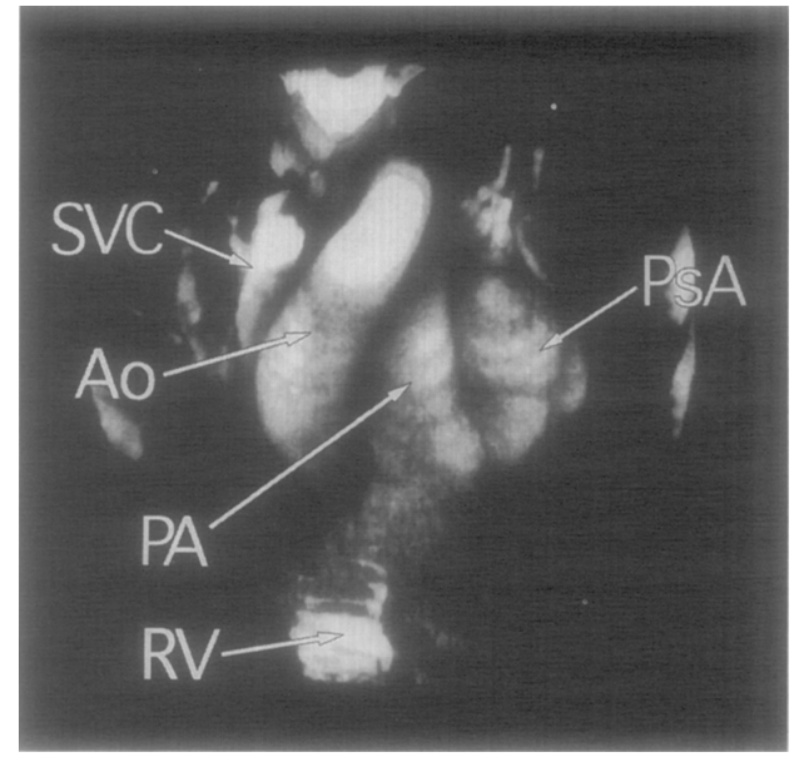

Fig. 1. Ultrafast CT scan demonstrating extension of the pseudoaneurysm around the pulmonary artery and the left atrium. $A O$, Aorta; $P A$, pulmonary artery; $P_{S} A$, pseudoaneurysm; $R V$, right ventricle; $S V C$, superior vena cava.

tionship with the left ventricular outflow tract, left atrium, pulmonary artery, and the aortic root.

In summary, we advocate routine use of ultrafast CT scanning in the diagnosis of valve endocarditis suspected to involve the mitral-aortic intervalvular fibrosa or the aortic anulus. The combination of ultrafast CT with TEE provides an accurate picture of the relationship of the pseudoaneurysm to adjacent structures and may obviate the need for ventriculography. Coronary arteriography should be used selectively in patients with symptoms of myocardial ischemia to demonstrate concomitant coronary disease or document dynamic coronary obstruction.

\section{REFERENCES}

1. Karalis DG, Bansal RC, Hauck AJ, et al. Transesophageal echocardiographic recognition of subaortic complications in aortic valve endocarditis: clinical and surgical implications. Circulation 1992;86:353-62.

2. Watarabz G, Haverich S, Spier R, et al. Surgical treatment of active endocarditis with paravalvular involvement. J Thorac Cardiovasc Surg 1994;107:171-7.

3. Afridi I, Apostolidou MA, Saad RM, et al. Pseudoaneurysms of the mitral-aortic intervalvular fibrosa: dynamic characterization using transesophageal echocardiographic and Doppler techniques. J Am Coll Cardiol 1995;24:137-45.

4. Jault F, Gandjbakhch I, Chastre JC, et al. Prosthetic valve endocarditis with ring abscesses: surgical management and long-term results. J Thorac Cardiovase Surg 1993;105:1106-13.

5. Parashara DK, Jacobs LE, Kotler MN, et al. Angina caused by systolic compression of the left coronary artery as a result of pseudoaneurysm of the mitral-aortic intervalvular fibrosa. Am Heart J 1995;129:417-21. 